\title{
Mechanical behavior and fractographic analysis of a TiNi alloy with various thermomechanical treatment
}

\author{
Anna Churakova ${ }^{1,2, *}$, Anna Yudahina ${ }^{1,2}$, Elina Kayumova ${ }^{2}$, and Nikita Tolstov ${ }^{2}$ \\ ${ }^{1}$ Institute of Molecule and Crystal Physics - Subdivision of the Ufa Federal Research Centre of the \\ Russian Academy of Sciences, 151 pr. Oktyabrya, 450075, Ufa, Russia \\ ${ }^{2}$ Ufa State Aviation Technical University, 12 K. Marx str., 450008, Ufa, Russia
}

\begin{abstract}
Influence of thermomechanical treatment (deformation, thermal cycling treatment in the temperature range of martensitic transformations B2-B19') on the TiNi alloys' mechanical behaviour and fracture was studied. Different states were considered, they are initial coarse-grained (CG), ultrafine-grained (UFG) after ECAP (with a grain size of $200 \mathrm{~nm}$ ), the state after ECAP and cold upsetting by 30\% - UFG state with high dislocation density. It was shown that thermal cycling causes some increase in dislocation density, strength and microhardness in all the states. Thermal cycling of UFG alloys allows forming the states with nonequilibrium grain boundaries, with additional dislocations of "phase hardening". The nature of the fracture was analysed in the TiNi alloy in various states.
\end{abstract}

\section{Introduction}

The TiNi-based alloys relate to a class of functional materials with shape memory effect (SME) caused by thermoelastic martensitic transformations [1-4]. These alloys are widely used as structural functional materials in engineering and medicine. Processing of ultrafinegrained (UFG) and nanocrystalline (NC) states by severe plastic deformation techniques allows increasing service properties of different metals and alloys including TiNi-based alloys [5, 6]. SPD techniques enable producing integral TiNi billets with ultrafine-grained (UFG), nanocrystalline (NC) and amorphized structures. The two most popular SPD techniques are high pressure torsion (HPT) and equal channel angular pressing (ECAP) [5]. HPT technique enables producing TiNi samples in the amorphized state, subsequent annealing may result in formation of an NC structure with a grain size starting from $20 \mathrm{~nm}$ [6]. The studies showed that TiNi alloys in the NC state with a grain size of about $50 \mathrm{~nm}$ demonstrated the highest service properties. However, the HPT technique allows producing only small-size discs for research. The ECAP technique enables producing large-size samples that can be applied in practice [5, 7 - 8]. But it is impossible to produce samples TiNi with a grain size less than $300 \mathrm{~nm}$ by ECAP processing, which means ultimately high properties are hard to be reached through application of this technique [7].

\footnotetext{
*Corresponding author: churakovaa_a@mail.ru
} 
Thermal cycling (TC) is a technique used for additional enhancement of strength properties in some alloys. However, thermal cycling in coarse-grained (CG) TiNi alloys does not lead to considerable phase hardening [9]. In case of TiNi some increase of the dislocation density takes place during multiple cycles of martensitic transformations, which is accompanied with a slight change of a martensitic transformation temperature and some enhancement of the yield stress during mechanical loading. The term «thermoelastic transformation» in the strict sense excludes any noticeable irreversible changes. However, the materials in the UFG and NC states are characterized with enhanced specific surface area of grains (S). Thus, grain boundaries as crystalline lattice defects can be dislocation nucleation centers during martensitic transformation, and therefore phase hardening during thermal cycling in UFG TiNi can intensify. Unlike the majority of other known materials with martensitic transformations (steels, etc), the temperatures of martensitic transformations in TiNi are close to the room one, that is why thermal cycling does not lead to relaxation of UFG and NC structures preliminarily formed in them [10].

However, hardening in deformed materials is explained by increased dislocation density, i.e. its nature differs from that in UFG materials, in which enhancement of the yield stress is conditioned by grain refinement and increase of the grain boundaries area. It is of special interest to establish the influence of the UFG state of TiNi alloys on the structural changes during thermal cycling through martensitic transformation temperatures, to determine the role of grain boundaries in dislocation generation at phase martensitic transformations, and to establish the possibility of mechanical and functional properties enhancement of these materials via phase hardening. There are a limited number of publications on studies of thermal cycling influence on UFG TiNi alloys [11-13]. However, the paper [11] is devoted mainly to the effect of mechanocycling on ECAP-processed TiNi. The papers $[12,13]$ mainly deal with the issues of dilatation in UFG TiNi alloys during thermal cycling.

The work [14] showed the effect on the microstructure of the TiNi alloy of multiple martensitic transformations in various states, but the nature of fracture and fractography in these materials after these treatments were ignored. In this work, we studied the mechanical behavior and fractography after various treatments.

\section{Material and methods}

The studies were carried out on $\mathrm{Ti}_{49.3} \mathrm{Ni}_{50.7}$ (at.\%) samples (manufactured by CJSC «Industrial center MATEX», Moscow) subjected to homogenizing water quenching from $800{ }^{\circ} \mathrm{C}$. The alloy is in the austenite state with a B2 structure (CzCl-type) at room temperature.

In order to form a UFG state, quenched cylinder samples (Ø20 mm, length of $100 \mathrm{~mm}$ ) were subjected to 8 ECAP cycles on a die-set with the angle of channels intersection of $120^{\circ}$ at $450^{\circ} \mathrm{C}$.

Separate samples after ECAP were subjected to additional deformation by cold upsetting by $30 \%$ to fabricate a UFG state with enhanced dislocation density and shear bands.

Thermal cycling treatment of samples in different initial states was carried out by cooling to the temperature of liquid nitrogen $\left(-196{ }^{\circ} \mathrm{C}\right)$ and heating to $150{ }^{\circ} \mathrm{C}$, which is a priori lower and higher than the temperatures of direct $\mathrm{Mf}$ and reverse Af martensitic transformations. The number of thermocycles «heating - cooling» was from 0 to 100 . The holding time at the heating and cooling temperatures was 3 minutes.

Calorymetric testing of the material was performed on a differential calorimeter Diamond Pyris (Perkin Elmer). In order to analyze the martensitic transformation temperatures, the differential scanning calorimetry (DSC) was performed on samples with a 
diameter of $4.5 \mathrm{~mm}$ and thickness of $0.5 \mathrm{~mm}$ in the temperature range from $-150^{\circ}$ to $150^{\circ} \mathrm{C}$. The heating and cooling rate was $20^{\circ} \mathrm{C} / \mathrm{min}$. The characteristic temperatures of martensitic transformations for this alloy in the quenched state are $\mathrm{Ms}=-32^{\circ} \mathrm{C}, \mathrm{Mf}=-62^{\circ} \mathrm{C}, \mathrm{As}=-29^{\circ} \mathrm{C}$, $\mathrm{Af}=-5^{\circ} \mathrm{C}$.

A fine structure of material was studied with a transmission electron microscope (TEM) JEM-2100 at an accelerating voltage of $200 \mathrm{kV}$. The foils for electron-microscopic studies were prepared on a twin jet electropolishing set «TenuPol-5» according to the standard procedure with the help of electrolyte $10 \% \mathrm{HClO} 4+90 \% \mathrm{CH} 3(\mathrm{CH} 2) 3 \mathrm{OH}(90 \%$ butanol). The voltage was $50 \mathrm{~V}$. Tensile mechanical tests were performed at room temperature with a test speed of 10-3 s-1 on a tensile machine designed at USATU. Fractography was studied using a scanning electron microscope (SEM) JEOL JSM 6395.

\section{Results and discussions}

In the initial CG state at room temperature the $\mathrm{Ti}_{49.3} \mathrm{Ni}_{50.7}$ has an austenite structure with a grain size of about $50 \pm 5 \mu \mathrm{m}$ according to SEM analysis (Fig. 1a). An analysis of the structure after thermal cycling with the number of cycles equal to 100 showed that the grain size in this case was $47 \pm 2 \mu \mathrm{m}$ (Fig. 1 b), in addition, martensitic relief is observed inside the grains.
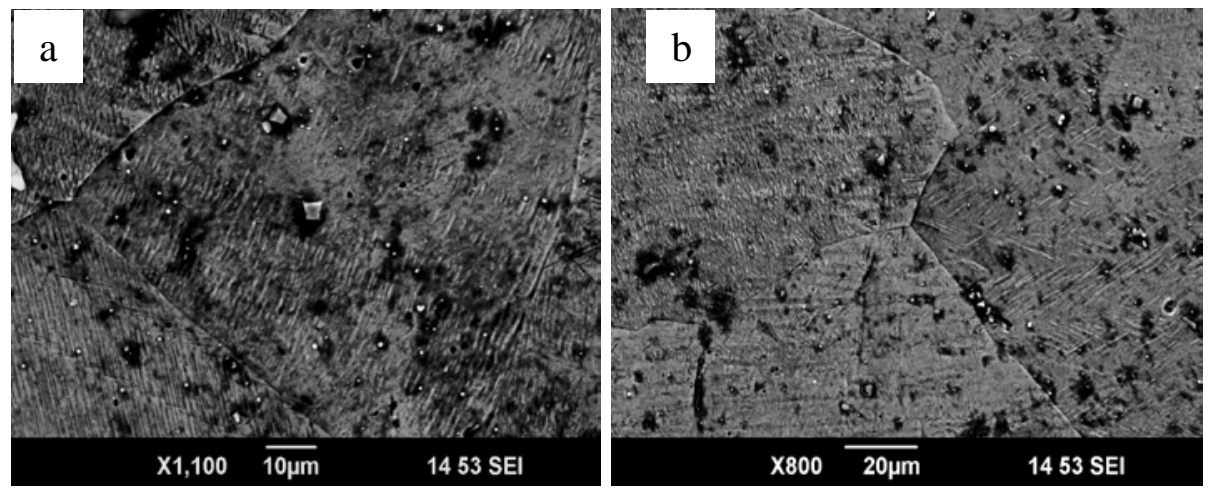

Fig. 1. SEM image of the structure of the $\mathrm{Ti}_{49.3} \mathrm{Ni}_{50.7}$ alloy in the CG state (a), after the TC $(\mathrm{n}=100)(\mathrm{b})$

After ECAP a UFG structure with a grain size of about $200 \mathrm{~nm}$ forms in TiNi (Fig. 2a). The analysis of TEM images enables assuming that thermal cycling with a number of cycles $n=100$ resulted in additional enhancement of dislocation density (Fig. 2 b).

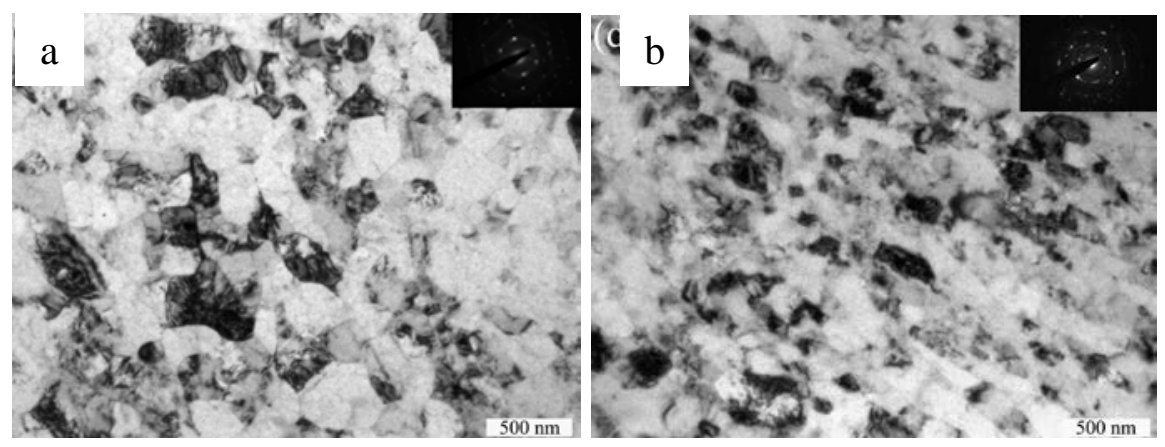

Fig. 2. TEM image of the structure of the $\mathrm{Ti}_{49.3} \mathrm{Ni}_{50.7}$ alloy in the UFG state (a), after the TC $(n=100)(b)$ 
Cold upsetting by $30 \%$ of an ECAP-processed sample usually leads to formation of deformation bands and significant increase of the dislocation density in the structure. The band width and the size of structural elements were about $50 \mathrm{~nm}$ (Fig. 3a). Thermal cycling leads to some increase of the dislocation density in separate structure areas (Fig. 3b), however, the TEM technique did not allow registering quantitative changes in the structure with the number of cycles increasing.
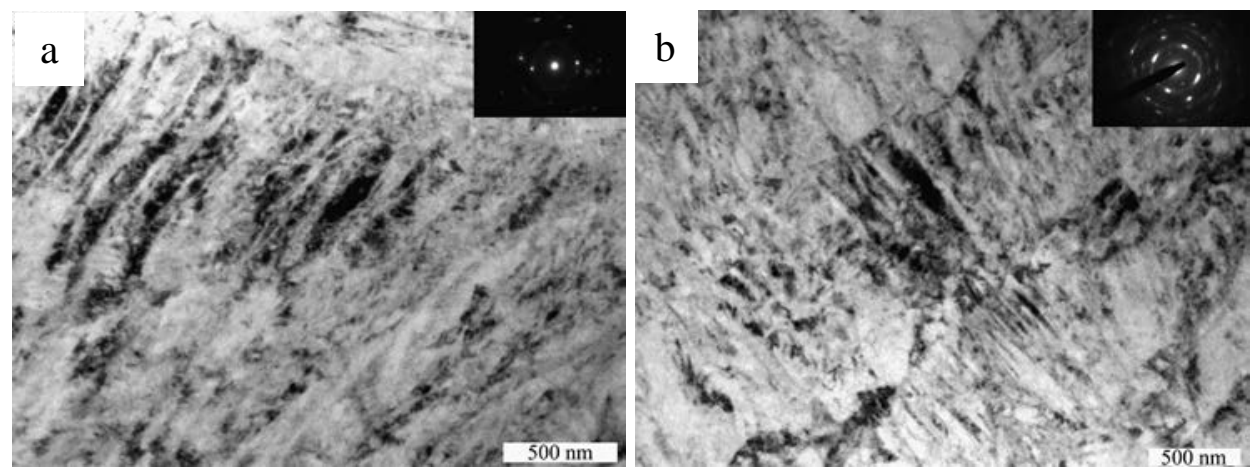

Fig. 3. TEM image of the structure of the $\mathrm{Ti}_{49.3} \mathrm{Ni}_{50.7}$ alloy in the UFG + cold upsetting state $(\mathrm{a})$, after the TC $(\mathrm{n}=100)(\mathrm{b})$

Table 1 lists the results of martensitic transformation temperature studies achieved through DSC.

Table 1. Characteristic temperatures of martensitic transformations.

\begin{tabular}{|c|c|c|c|c|c|c|}
\hline \multirow{2}{*}{ State } & \multicolumn{5}{|c|}{ Temperature, ${ }^{\circ} \mathrm{C}$} \\
\cline { 2 - 7 } & $\mathrm{M}_{\mathrm{s}}$ & $\mathrm{M}_{\mathrm{f}}$ & $\mathrm{A}_{\mathrm{s}}$ & $\mathrm{A}_{\mathrm{f}}$ & $\begin{array}{c}\mathrm{M}_{\mathrm{s}}- \\
\mathrm{M}_{\mathrm{f}}\end{array}$ & $\mathrm{A}_{\mathrm{s}}-\mathrm{A}_{\mathrm{f}}$ \\
\hline quenching (CG) & -32 & -62 & -29 & -5 & 30 & 24 \\
\hline quenching (CG) + TC* & -6 & -41 & -39 & -2 & 35 & 37 \\
\hline ECAP (UFG) & -23 & -47 & -11 & 3 & 24 & 14 \\
\hline ECAP (UFG) + TC* & 27 & -12 & -3 & 32 & 39 & 35 \\
\hline ECAP + upsetting & - & - & - & - & - & - \\
\hline $\begin{array}{c}\text { ECAP + upsetting + } \\
\text { TC* }\end{array}$ & - & - & - & - & - & - \\
\hline
\end{tabular}

The analysis of calorimetric data allows drawing conclusion that thermal cycling result in increase of martensitic transformation temperatures, especially of Ms and Mf. The most significant increase of Ms and Mf temperatures is observed for the UFG state (by $50^{\circ}$ and $35^{\circ} \mathrm{C}$, respectively), whereas in the CG state the temperatures $\mathrm{Ms}$ and $\mathrm{Mf}$ increase approximately by $25^{\circ} \mathrm{C}$. In the UFG alloy as a result of TC the Af temperature also increases significantly (by $29^{\circ} \mathrm{C}$ ). At the same time in the $\mathrm{CG}$ alloy the temperatures As, Af change insignificantly as a result of TC. It was shown earlier in some papers [4] that during thermal cycling of CG TiNi the martensitic transformation temperatures Ms and Mf slightly decrease. According to our investigations, martensitic transformation temperature increases in TiNi as a result of TC. This can be conditioned by alloy ageing due to the used thermal cycling regimes or by intermediate R-transformation. This phenomenon requires additional studies to be performed. 
The DSC technique did not allow determining the martensitic transformation temperatures in the state ECAP+upsetting and ECAP+upsetting+TC. One might assume that martensitic transformations are blocked in severely deformed state ECAP+upsetting. However, as TC leads to microhardness growth, martensitic transformations take place in this state. However, they occur in different areas of a sample at different temperatures due to microstructure inhomogeneity, as a result separate transformation peaks are not determined by DSC.

The ultimate tensile strength $\sigma_{\text {UTS }}$ of $\mathrm{Ti}_{49.3} \mathrm{Ni}_{50.7}$ in the CG state is $820 \mathrm{MPa}$ and increases to $900 \mathrm{MPa}$ during thermal cycling due to phase hardening. Deformation-induced martensitic transformation as a phase pseudo-yield plateau typical of the CG state is observed on the plots. The ductility reduced from 36 to $31 \%$ as a result of thermal cycling.

Much higher strength and similar phase yield stress values (1310 and $450 \mathrm{MPa}$ respectively) are typical of the UFG state. Thermal cycling insignificantly increases the strength of the UFG state to $1360 \mathrm{MPa}$. In the state after ECAP and upsetting (UFG+upsetting) the ultimate tensile strength was $1750 \mathrm{MPa}$, the thermal cycling enabled achieving the ultimate tensile strength by $200 \mathrm{MPa}$ up to $1960 \mathrm{MPa}$ with a ductility of 26 $\%$. It should be noted that the curve rate for the state with high density of defects differs from that for CG and UFG states. There is no phase pseudo-yield plateau on the curves, which testifies to blocking of deformation-induced martensitic transformation. The yield stress increases by 70 and $140 \mathrm{MPa}$ in the UFG and UFG+upsetting states, respectively (Table 2).

Table 2. Results of mechanical tensile tests of $\mathrm{Ti}_{49.3} \mathrm{Ni}_{50.7}$ in different states.

\begin{tabular}{|c|c|c|c|c|}
\hline State & бUTs, MPa & $\sigma_{\mathrm{M}, \mathrm{Mpa}}$ & $\sigma \mathrm{Ys}, \mathrm{MPa}$ & $\delta, \%$ \\
\hline Quenching & $820 \pm 10$ & $440 \pm 10$ & $520 \pm 10$ & $36 \pm 1$ \\
\hline quenching + TC & $900 \pm 10$ & $620 \pm 15$ & $640 \pm 10$ & $31 \pm 2$ \\
\hline ECAP & $1310 \pm 10$ & $450 \pm 12$ & $1130 \pm 10$ & $29 \pm 2$ \\
\hline ECAP+TC & $1360 \pm 15$ & $530 \pm 10$ & $1200 \pm 12$ & $31 \pm 3$ \\
\hline ECAP+upsetting & $1750 \pm 20$ & - & $1410 \pm 15$ & $22 \pm 2$ \\
\hline ECAP+upsetting+TC & $1910 \pm 15$ & - & $1550 \pm 10$ & $26 \pm 3$ \\
\hline
\end{tabular}

After mechanical tensile tests, an analysis of the fracture of the samples was carried out using a scanning electron microscope. The microrelief of sample fractures after quenching is characteristic of quasibrittle fracture (Fig. 4). A fracture with slightly curved surfaces or facets is formed due to the merging of individual cracks. Over the entire area of fracture, with a large increase, detachment pits and micropores are clearly visible. Quasiscole sites often mix with separation pits during viscous failure. The average size of the pits is 2.8 microns. 


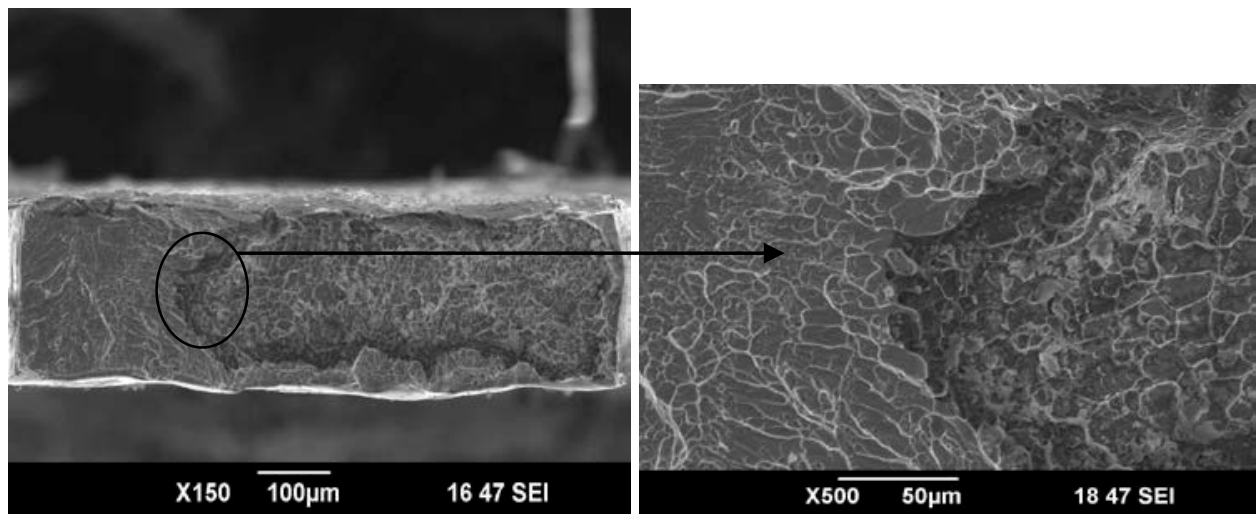

Fig. 4. Fracture (SEM) of $\mathrm{Ti}_{49.3} \mathrm{Ni}_{50.7}$ alloy after quenching

In the CG + TC state, an inhomogeneous kink is observed; its microrelief is divided into two zones - viscous and quasi-brittle fractures (Fig. 5). A characteristic feature of viscous fracture is the slow development of cracks and high energy intensity, as well as a large number of pits on the relief. The average size of the pits is 2.3 microns.
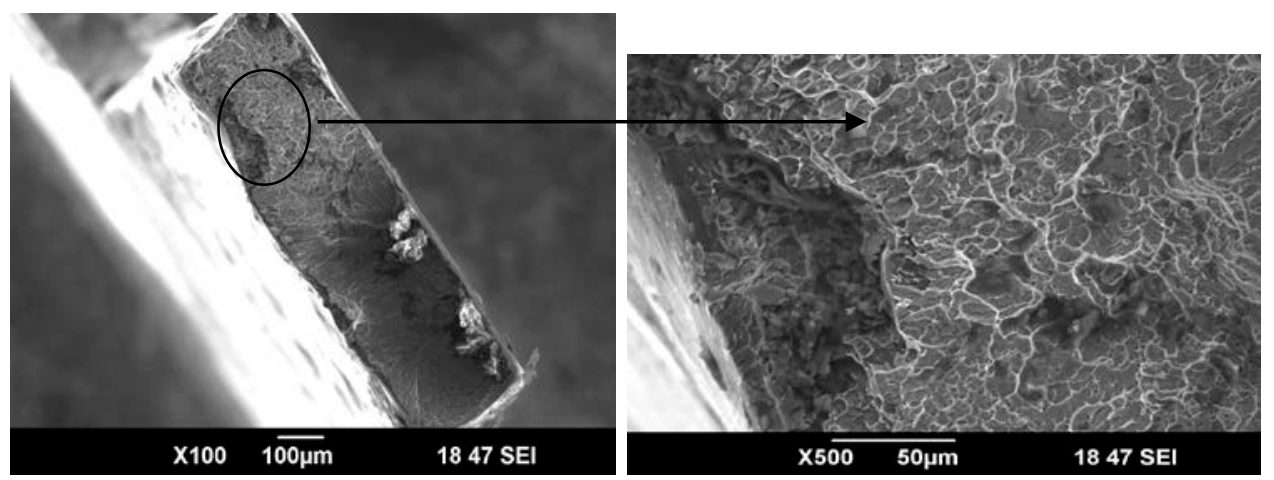

Fig. 5. Fracture (SEM) of $\mathrm{Ti}_{49.3} \mathrm{Ni}_{50.7}$ alloy after quenching + thermal cycling

The microrelief of sample fractures after ECAP processing is typical for viscous fracture with characteristic pits and a structure characteristic of this fracture (Fig. 6, a). The average size of the pits is 1.5 microns. After thermal cycling in a specimen with UFG structure, the microrelief of fractures is characteristic of the viscous fracture type (Fig. 6, b). A characteristic feature of this fracture is the slow development of cracks and high energy intensity. A viscous fracture has a high fibrillation. It consists of a relatively flat

al part of the fracture, and the lips of $^{\mathrm{f}}$ tho slice are present at the edges. The fracture

$\mathrm{a}$ ces thus formed contain numerous $\mathrm{i}$ b tations (pits). The average size of the pits is $1.4 \mu \mathrm{m}$. In this sample, the pits have mainıy equiaxial shape. 

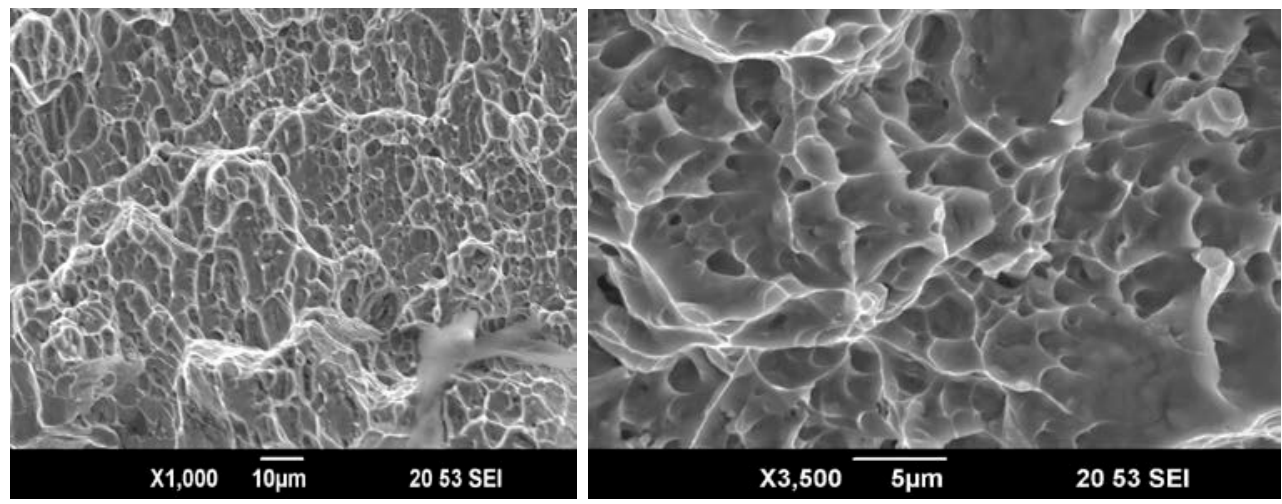

Fig. 6. Fracture (SEM) of $\mathrm{Ti}_{49.3} \mathrm{Ni}_{50.7}$ alloy after ECAP (a) and subsequent thermal cycling (b)

The microrelief of sample fractures after equal channel angular pressing and subsequent upsetting is divided into two zones (Fig. 7, a). One zone in the center of the fracture has an even relief with equiaxed pits throughout the area. The second zone occupies the periphery of the fracture and consists of separation ridges, covered with small pits. The average size of the pits is 1.2 microns. This microrelief is characteristic of viscous fracture. The microrelief of sample fractures after equal channel angular pressing and subsequent upsetting and thermal cycling is characteristic of viscous fracture. A non-uniform kink is inherent of fracture (Fig. 7, b). As in previous samples, equiaxed dimples are visible under high magnification. The average size of the pits is $1 \mu \mathrm{m}$.
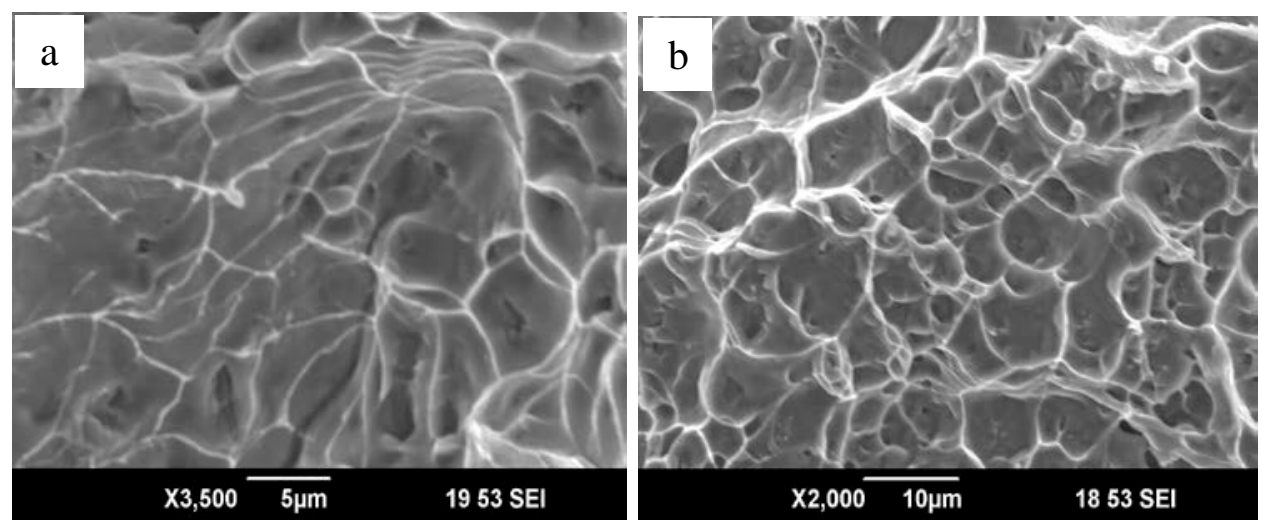

Fig. 7. Fracture (SEM) of $\mathrm{Ti}_{49.3} \mathrm{Ni}_{50.7}$ alloy after ECAP + upsetting (a) and subsequent thermal cycling (b)

\section{Conclusions}

1. As a result of thermal cycling the microhardness of the alloy in the CG and UFG states increases. The highest microhardness increment is observed in the UFG alloy as a result of thermal cycling after preliminary upsetting (the initial state is with the most refined structure).

2. A set of enhanced mechanical properties, namely strength, yield stress, ductility, is achieved as a result of the combined treatment that includes ECAP, upsetting and thermal cycling. 
3. In the CG state the microrelief of fractures is characteristic of quasibrittle fracture; after ECAP processing, the fracture character is viscous. With each subsequent processing of the UFG samples, the depth of the pits and the average size decrease.

This work was supported by the Grant of the Bashkortostan Republic of Russian Federation to young scientists (№28 GR from 07.03.2019).

\section{References}

1. V. Brailovski, S. Prokoshkin, P. Terriault, F. Trochu et al., Shape memory alloys: fundamentals, modeling and applications (ETS Publ., Montreal, 2003)

2. K. Otsuka, C.M. Wayman et al., Shape memory materials (Cambridge University Press, Cambridge, 1999)

3. V.N. Khachin, V. G. Pushin, V. V. Kondratiev, Titanium nickelide, structure and properties (Nauka, Moscow, 1992) (in Russian)

4. V.E. Gunter, Medical Materials and Implants with Shape Memory (TSU, Tomsk, Russia,1998)

5. S. Miyazaki, T. Imai, Y. Igo, K. Otsuka, Metall. Trans.17A, 115-120 (1986)

6. R.Z. Valiev Progr. Mater. Sci. 45, 103-189 (2000).

7. D.V. Gunderov, A.V. Lukyanov, E.A. Prokofiev, A.R. Kilmametov, V.G. Pushin, R.Z. Valiev Mater. Sci. Eng. A 503, 75-7 7(2009).

8. R.Z. Valiev, D.V. Gunderov, E.A. Prokofiev, V.G. Pushin, Yuntian Zhu Materials Transactions 49 (1), 97-101 (2008).

9. D. Gunderov, A. Lukyanov, E. Prokofiev, A. Churakova, V. Pushin, S. Prokoshkin, V. Stolyarov, R. Valiev, Materials Science Forum 738-739, 486-490 (2013).

10. Liu Y, McCormick PG Acta Metall. Mater. 38, 1321-1326 (1990).

11. AA Churakova, DV Gunderov, AV Lukyanov, YuA Levedev Letters of Materials 3, 166-168 (2013).

12. YX Tong, F Chen, B Guo, B Tian, L Li, YF Zheng, DV Gunderov, RZ Valiev Materials Science and Engineering A 587, 61-64 (2013).

13. RI Babicheva, KhYa Mulyukov Letters on materials 1, 156-161 (2011).

14. A.A. Churakova, D.V. Gunderov, Acta Metallurgica Sinica (English Letters) 28(10), 1230-1237 (2015). 